\title{
The Contribution of Personal and Social Resources towards the Prediction of Ethiopian Students' Academic Achievements
}

\author{
Esther Kalnisky ${ }^{1 *}$, Rina Brenner ${ }^{2}$ \\ ${ }^{1}$ Achva Academic College, Arugot, Israel \\ ${ }^{2}$ Kibbutzim College of Education, Israel
}

*Corresponding Author: Esther Kalnisky: kester@macam.ac.il
Citation: Kalnisky E., Brenner R. (2016) The Contribution of Personal and Social Resources towards the Prediction of Ethiopian Students' Academic Achievements. Open Science Journal 1(3)

Received: $8^{\text {th }}$ August 2016

Accepted: 30 ${ }^{\text {th }}$ September 2016

Published: $11^{\text {th }}$ October 2016

Copyright: (C) 2016 This is an open access article under the terms of the Creative Commons Attribution License, which permits unrestricted use, distribution, and reproduction in any medium, provided the original author and source are credited.

Funding: The author(s) received no specific funding for this work.

Competing Interests: The author have declared that no competing interests exists.

\section{Abstract}

The present research deals with the prediction of the academic achievements of students of Ethiopian origin in Israel. It seeks to explore the contribution of personal and social resources towards the success of these students in academic studies, in light of the poor achievements of Ethiopians in the conventional measures such as the Psychometric Entrance Test (PET) (Almagor-Lotan \& Koch Davidovitz, 2011). Two classes of Ethiopian students from two colleges of education were investigated and compared with students from a control group. Besides the significant differences in the characterizations of the background data of the two groups, in their first-semester grades and in their personal resources, the Ethiopians manifested their own unique characteristics which include highly-focused future study goals, a low level of self-criticism, and lofty perceptions of coherence (control) and self-efficacy — all of which predict academic achievements.

Keywords: Students, Achievements, Personal and Social Strengths 


\section{Introduction}

The standard acceptance procedures for academic studies in Israel and in the USA (Feivish \& Goldschmidt, 2006) are based on cognitive measures. These measures are sometimes inconsistent with the prevailing conception among lecturers in institutions of higher education who relate to the abilities and personal efforts invested by the students.

In contrast to the cognitive measures, research shows that personal and social characteristics are also likely to constitute incentives towards success in academic studies (Shulman, author, \& Shahar, 2009). Thus, it is also found in longitudinal research that predicts success in life as well (Dietrich, Shulman, \& Nurmi, 2013). Among the populations whose collective achievements are low in relation to the majority of those who take the PET as a precondition for acceptance to university are the Arab residents of Israel (Karlitz, Ben-Simon, Ibrahim, \& Eviatar, 2014). In addition, they also include migrants from countries with different cultural trait, such as migrants from Africa (Almagor-Lotan \& Koch Davidovitz, 2011; Feivish \& Goldschmidt, 2006).

Israeli children grow up with messages of excellence that frequently generate competitiveness and motivation for significant achievements at a limited time. Not only do these educational values come to the fore later in these children's behavior patterns in various areas of life, but they also affect children's performance in stressful situations such as university entrance examinations.

In contrast, the achievements of migrant groups are at times jeopardized by the objective evaluation methods that require western patterns of thinkinglimited time performance and competitiveness. The migrants from Ethiopia to Israel are numbered among them, and they include those born to native Ethiopian parents in Israel (the second and first-and-a-half generations) who are applying to study in institutions of higher education.

The present research, which constitutes a part of an overall longitudinal study, examined the personal and social resources of Ethiopian students when applying for academic studies. The purpose of this study is to tackle the challenge facing the higher education system, and to find complementary tools for predicting the candidate's academic success.

\section{Theoretical Background}

\section{Ethiopian Migrants to Israel from the Second and First- and-a-Half Generations in Higher Education}

Israel, an immigrant-absorbing country, contains a considerable percentage of citizens who are migrants from various countries worldwide and hail from various cultural, linguistic, and traditional backgrounds. One of the groups on Israel's demographic map comprises of immigrants from Ethiopia and their offspring. However, Ethiopian migrants arrived in Israel mainly in 1984 and 1991 in two large waves of immigration pursuant to international agreements.

The children who were born in Israel to native Ethiopian parents are designated "second generation", while those who were born in Ethiopia and 
immigrated to Israel prior to adolescence are termed "a generation and a half" (Cohen \& Haberfeld, 2003; Lev Ari, 2012). The members of the latter group underwent a substantial part of their socialization process in Ethiopia prior to their immigration to Israel. Examining the data pertaining to the integration of the second and first-and-a-half generations into the secondary-school education system, Cahan-Stravachinsky, Levy, and Constantinov (2012) painted a gloomy picture according to which one-third of the Ethiopian youngsters experience difficulty with the core subjects in secondary school. It was expected that the longer they had been in Israel, the more their achievements would improve and the more their disparities would decrease; however, the data attest to a trend of deteriorating achievements.

The percentage of Ethiopian students in institutions of higher education is not consistent with their proportion in the population $(2 \%)$. This is borne out by perusing several comparative data. Therefore, in the 2013-2014 academic year, only $0.9 \%(2,785)$ of all students studying in institutions of higher education were Ethiopian (CBS, 2013). In 2007, the average collective results in the Ethiopians' PET were 108 points lower than those of the rest of the population (AlmagorLotan \& Koch Davidovitz, 2011). This is a significant difference when the points range from 200 to 800 .

It is possible that their low representation in higher education is a consequence of prior disparities during their secondary-school years. For instance, in 2012-2013, the rate of eligibility for a matriculation certificate among Ethiopians reached $54 \%$ (it was slightly higher among 12th-grade native-born Ethiopian students than among those belonging to the second generation: $52 \%$ vs. $48 \%$ ) as opposed to $63 \%$ of all those tested in the Hebrew education system. However, eligibility for a matriculation certificate alone does not ensure university entrance, and it is necessary to produce a suitable certificate that fulfills the university's requirements. That same year, only about $26.5 \%$ of the Ethiopian students were eligible for a matriculation certificate. (This was higher among the members of the second generation-31\% - as compared with $21 \%$ among the first generation). The percentage of all those that were eligible for a matriculation certificate in the Hebrew education system was 52.5\% (CBS, 2013).

It is possible that the achievements were affected also by the perpetuation of some patterns of the original culture - for instance, performing the psychometric tasks slowly instead of reacting quickly, which is liable to sabotage the chances of being accepted to higher education (Ben-Ezer, 2007; King \& Valda Tzadik, 2006). Consequently, it is also possible that poor achievements result from the students' lack of proficiency in the dominant language, linguistic literacy deficiencies, and difficulties in language acquisition (Cook Golan, 2008; Schleifer, 2007).

Some of them, particularly those who immigrated in 1984, experienced vicissitudes and traumatic situations in their lives, for instance, the journey to Israel via the refugee camps in Sudan, change in the role and status of the family in the new land, and coping with a discriminating and threatening environment (Mana, Or, \& Mana, 2004; Shabtai, 2001). The crisis undergone by the immigrants accompanies their offspring to this day in the various functions they perform as parents and as seekers of education and employment.

Frequently, in critical situations, people can develop personal and interpersonal abilities that serve as strategies for coping with and adapting to the new society, higher education, and employment on the one hand, and as measures 
of social mobility on the other hand (Author, 2013). Ethiopian women have been found to be endowed with more significant coping powers than the men (Shabtai \& Kasan, 2005).

Despite the personal and social difficulties, there are Ethiopians who overcame them and succeed in attaining their achievements. The combination of the difficulties described above and personal coping resources piqued the researchers' intellectual curiosity: Who are the Ethiopians who succeed despite the objective difficulties? What characterizes them? In what manner do personal and social characteristics affect their entry into academia and their success therein?

While the authors of this article do not ignore the weight of cognitive abilities in academic studies, they relate to them as part of the individual's entire personality and of the human environment in which that individual functions.

\section{Personal and Social Resources}

According to the Theory of Self-Definition and Personal Relatedness (Blatt \& Blass, 1996), a healthy lifestyle is supported by two central pillars: interpersonal relatedness and self-definition. The concept of interpersonal relatedness describes close, developing, and protective interpersonal relations. The concept of selfdefinition describes the individual's need to build a coherent feeling of self for himself (Antonovsky \& Sagy, 1986) — a feeling that is stable, realistic, and positive. The theory's claims have been supported by the research; also, the successful integration of the two central axes of relatedness and self-definition leads to optimal development and obviates psychopathological situations (Blatt, Shahar, \& Zuroff, 2001).

These resources may well be beneficial to processes of adapting to a new workplace, acceptance to a university, and to a sense of belonging to the community (Romano, 2015). Their importance as tools for personal and interpersonal adaptation has increased in the past decades in view of the phenomena that characterize postmodern society: migration, absence of employment availability, intensification of the criteria limiting acceptance to institutions of higher education, and so on.

\section{Personal Resources: Life Goals, A Sense of Efficacy and Success, and Coping Resources}

In an optimal situation, young people are able to develop themselves without losing their sense of self. They are able to aspire towards achievements and selfdefinition without jeopardizing interpersonal relations. The findings of various studies have consistently shown a high sense of self-efficacy and low self-criticism to be good predictors of situations of adaptation. Self-criticism does not lead to positive self-definition, nor does it predict effective adaptation, as opposed to a sense of efficacy, which does predict effective adaptation (Shahar, Henrich, Blatt, Ryan, \& Little, 2003).

However, these personal resources may consist of several types: innate tangible resources (such as social status, gender, ethnic group), or acquired, intangible resources (such as acquired education, motivational factors, a sense of efficacy, coping strategies). The members of the Ethiopian community in Israel, as a characterized group of migrants, do not enjoy resources since, they belong mainly to a low socioeconomic class, their skin color is not considered to be an 
advantage in a western society, and their cultural assets are not appreciated as means of advancement in society.

As opposed to the absence of tangible resources, it has been found that intangible resources such as personal and social resources may bolster populations with few chances of advancing in the society (Author, 2007). The starting-point of the present research posits that Ethiopian immigrants develop coping strategies as a way of adapting to the new society and to altered life situations such as acceptance to studies. This basic premise guides the research and contends that these resources differentiate between the individuals who succeed in entering the portals of higher education and those who do not.

One of the resources that contributes to effective adaptation is the perception of personal goals and the development of a sense of obligation to those goals (Dietrich et al., 2013; Shulman \& Nurmi, 2010)

The Self-Determination Theory (Ryan \& Deci, 2000a) presents additional skills that enhance behaviors of self-regulation and autonomy, namely; selfperception of competency, autonomy, and a sense of belonging. The theory also relates to motivation as a personal resource and differentiates between intrinsic and extrinsic motivation (Assor, 2012). Shahar et al. (2003) found self-criticism to be associated with a lack of self-regulation and also to operate as a factor that prevents the individual from undergoing a positive experience. In contrast, the sense of self-efficacy has been found to be linked to inner regulation. In another study (Shahar, Author, Shulman, \& Blatt, 2006), it was found that (1) young adults with a highly-developed sense of self-efficacy invest in their goals, and (2) a motive of their behavior was a powerful intrinsic motivation. Conversely, individuals with a high level of self-criticism are identified with a low level of intrinsic motivation, with an absence of motivation, and with a negative assessment of their chances of achieving their personal goals.

To sum up, the above-mentioned models of personality-linked resources furnish a research basis according to which variables such as future personal goals, perception of coherence, sense of self-efficacy, low level of self-criticism, and inner motivation explain and predict success in life. This study examines personal and social capital as assets of the candidates for higher studies who hail from the Ethiopian community - individuals who have fewer chances of being accepted to studies, according to the standard classification criteria, as a result of the factors mentioned previously.

\section{Social Resources: Support}

The family as a social resource provides the initial and most important social, emotional, interpersonal, economic, and cultural context for the individual's development. It has been found that risk factors in the family exert a significant influence on young people's development (Sanders \& Ralph, 2005). A longitudinal study has revealed that depression and low self-esteem are predictable during early adolescence as a result of the relationship with the parents (Bridges, Flores, Tschann, \& Operario, 2006; Galambos, Barker, \& Krahn, 2006).

Migrants experience the migration crisis in the family setting as well-in changes in parenting patterns, with all of the attendant implications, and mainly in the context of the second and first-and-a-half generations (Edelstein, 2002).

In addition, external sources of social support also play a meaningful role in development and in the transitions between secondary school and work, and from 
university to the world of employment. In these cases, extra-familial social resources such as friends and partners have been found to predict a good and a long-term adaptation (Shulman \& Connolly, 2013).

To sum up, research findings indicate low achievements of an immigrant population in the standard university acceptance tests. In parallel, the professional literature also points to the contribution of personal, social, and situational factors (Wilson, Ward, \& Fischer, 2013) resources in coping with these situations. Therefore, the aim of this study is to investigate the contribution of the above resources when embarking on higher education, thereby combining the two types of findings among the Ethiopian students.

\section{Method}

\section{Sample}

The sample comprised two groups of students who were accepted into academic study programs offered by two colleges of education in Israel. These programs, which nurture Ethiopian students and render the higher education system accessible to them, were held during the 2013-2014 and 2014-2015 academic year. The Ethiopian students spent their first year at the two colleges and constituted the research group $(61.3 \% ; \mathrm{N}=68)$. In addition, another group of first-year students at the same colleges was examined $(38.7 \% ; \mathrm{N}=43)$; this group had been accepted via a standard acceptance process, and it constituted the control group.

As concerns the gender variable, a striking characteristic of colleges of education in Israel, including the two that participated in this research, shows the fact that majority of the students were women $(90 \% ; \mathrm{N}=99)$ as opposed to men $(10 \% ; \mathrm{N}=11)$.

From the point of view of educational characteristics, most students $(77.6 \%$; $\mathrm{N}=83)$ held matriculation certificates, and only $22.4 \%(\mathrm{~N}=24)$ held certificates from preparatory courses. Of the students' mothers, $23.8 \% \quad(\mathrm{~N}=15)$ had no education, $60.3 \% \quad(\mathrm{~N}=38)$ had elementary education, $14.3 \% \quad(\mathrm{~N}=9)$ held an academic degree, and only $1.6 \%(\mathrm{~N}=1)$ had completed certification studies or courses. With regard to the fathers' education, $20.0 \%(\mathrm{~N}=11)$ had no education at all, $63.6 \%(\mathrm{~N}=35)$ had elementary education, $14.5 \%(\mathrm{~N}=8)$ had studied for an academic degree, and $0.9 \%(\mathrm{~N}=1)$ had completed certification studies or courses. As regards the students' and their parents' participation in the employment market, $70.2 \%(\mathrm{~N}=73)$ of the students worked for a living at jobs, as opposed to $29.8 \%(\mathrm{~N}=31)$ who did not work. More students' mothers worked $(71 \% ; \mathrm{N}=66)$ compared to student's mothers who did not work $(29 \% ; \mathrm{N}=27)$. However, the numbers are similar regarding student's fathers' work: $76.7 \%(\mathrm{~N}=66)$ worked as opposed to $23.3 \%(\mathrm{~N}=20)$ who did not. 


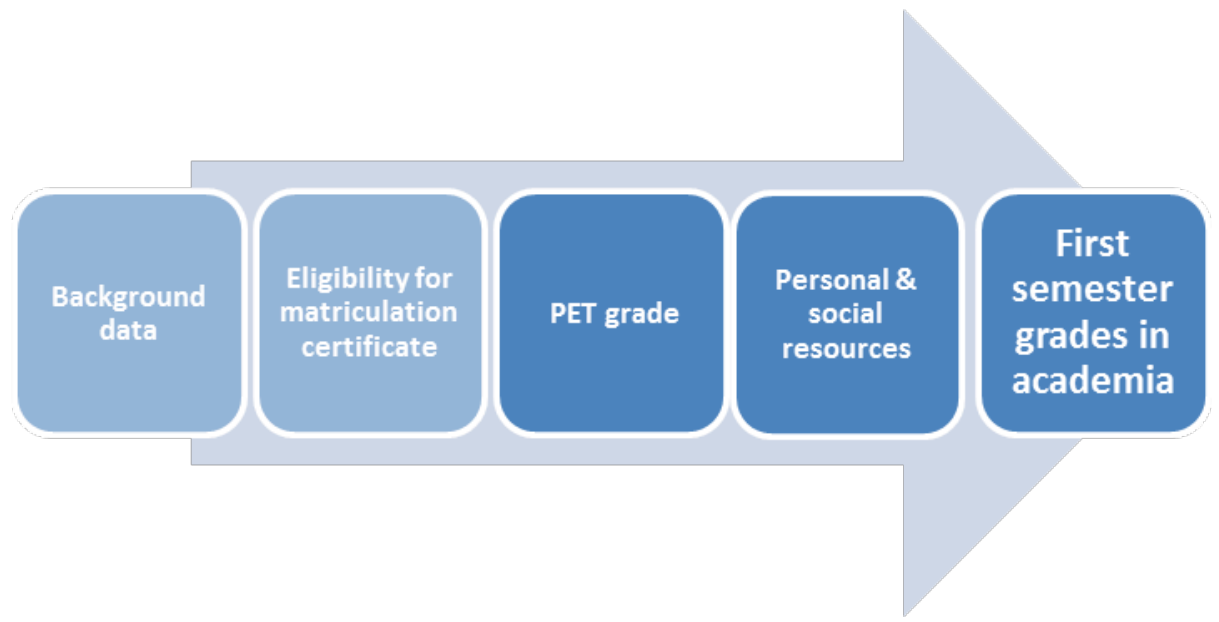

Figure 1. Model of the variables that were examined

(Note. In this study, all the variables in the model were examined, but the prediction of the grades was examined only according to the PET grade and personal and social resources.)

\section{Tools}

\section{Personal Resources}

Personal Goals: PPA - an adjusted version of the scale for analyzing future plans (Little 1983). The research participants reported on three future personal goals in various areas of life: higher education; profession or work; romantic relationships; family; friends; topics linked to oneself and to health; hobbies and entertainment; and so on. Every goal had to be evaluated: its importance, commitment to it, extent of the progress toward achieving it, chances of achieving it, extent of the control over achieving it, extent of other people's support as regards achieving it, extent of other people's hindrance as regards achieving it, and extent of the pressure to achieve it.

Sense of Efficacy, Criticism, and Expectation of Success: Three closed questions were devised in order to examine self-perception as regards efficacy and criticism. Studies have found these variables to be associated with achieving goals in life and with succeeding in pre-academic preparatory studies (Author, 2007). In addition, they were also found to be associated with achieving goals over the years (Dietrich et al., 2013; Nurmi, 2013).

Furthermore, as a measure of the perceptions of success and self-efficacy, three questions were devised in order to examine the personal perception as regards achieving personal goals (perception of success in the present, ability to achieve goals in the future, and personal progress toward the goals in comparison to other people).

Coping Resources - Coherence: The coherence questionnaire (Sense of Coherence Scale; Antonovsky, 1993) consists of 29 statements on a 7 -step scale which examines the extent of confidence that people have in themselves and in the surrounding world, their sense of efficacy, and their understanding of the reality in which they live. The sense of coherence is examined on the basis of three measures: comprehensibility - the measure according to which the individual perceives the world as predictable, manageability - the measure according to which the individual understands that he/she has resources and the ability to cope with various situations, and meaningfulness - the measure 
according to which the individual finds interest and emotional meaning in what he/she does in life.

As has been determined in previous studies, the questionnaire possesses a high degree of inner reliability (between $\alpha=.83$ and $\alpha=.69$ ) (Al-Krenawi \& Slonim Nevo, 2009; Tartas, Walkiewicz, Budzinski, Majkowicz, \& Wojcikiewicz, 2014).

Motivation: The questionnaire is an adaptation of the original one that examines self-regulation (Self-Regulation Questionnaire, Ryan, \& Connell, 1989). The 28 items indicate three types of motivation: (1) inner/intrinsic motivation; (2) external/extrinsic motivation; and (3) indecision and path-seeking relating to motivation.

The examination of the inner reliability of the scales pointed to a high level of reliability of the three areas of motivation, as follows: inner motivation $(\alpha=.85)$, external motivation $(\alpha=.84)$, and indecision regarding motivation $(\alpha=.81)$. Similar to previous studies (Little, Cunningham, Shahar, \& Widaman, 2002), who found high reliability in the range of $\alpha=.84-.93$, the entire questionnaire possesses a high level of inner reliability $(\alpha=.85)$.

\section{Social Resources}

The Network of Relationship Inventory (N.R.I.) (Furman \& Buhrmester, 1985): The questionnaire seeks to characterize the individual's network of relationships as regards the people in his/her immediate social environment according to the following categories: trust, esteem, care, intimacy, affection, and cooperation, as well as the subject's satisfaction with the above-mentioned relationships and the extent of their importance to him/her. Subsequently, five relationships were chosen: father, mother, friends, spouses, and other people close to the subject on whom the student was asked to report. The tool has been reported in the professional literature (Furman \& Buhrmester, 1992; Author, $2007)$ as possessing a high degree of reliability $(\alpha=.87)$.

\section{Achievement}

Grade on the PET: This grade was only submitted by some of the students $(\mathrm{N}=68)$. The reason being that in one of the colleges that was examined, the PET grade was not included among the Ethiopian students' acceptance requirements owing to considerations of bias that stem, as studies attest, from the subject's origin-be it Ethiopian (Tzuriel \& Kaufman, 1999) or Arab (Karlitz et al., 2014). Due to the conditions referred to above, the missing data were completed by conducting a Missing Value Analysis Estimation: EM.

First-semester Grades: The academic achievement variable included the grades obtained in the subject that is central to teaching, namely, pedagogy and the overall grade average. Due to the paucity of subjects, a Missing Value Analysis Estimation, EM, was conducted.

\section{Research Aim and Research Question}

The research aims to examine the contribution of personal and social resources towards the prediction of Ethiopian candidates' success in their studies as well as the standard quantitative aspects, namely, the results of the PET and the matriculation examination. Thus, the two research questions are as follows: 
1. What characterizes the Ethiopian candidates in their quest for higher education in the colleges as opposed to the general student population?

2. To what extent are social and personal resources (motivation, future goals, sense of efficacy, and perception of coherence) likely to predict academic achievements among this population?

\section{Research Procedure}

This research constitutes a longitudinal study that traces the progress of Ethiopian students in the academic teacher preparation system. The results of the first (pilot) stage of the research in which personal and social characteristics of Ethiopian candidates who were accepted primarily to teacher education are presented here. There is also a continuing program to trace the integration of the subjects at a later stage in their studies.

First Examination: This was conducted during the acceptance process. Besides the formal, mainly education-linked data that are standard during acceptance to colleges of education, the Ethiopians and the control group completed the questionnaires.

Second Examination: This was conducted at the end of the first semester. The students' grades obtained in the pedagogy course were examined, as was their overall grade average.

\section{Findings}

\section{Characteristics of Ethiopian Students}

In response to the first research question, the salient finding in the present study reveals that Ethiopian students constitute a group with unique characteristics that differentiate it clearly from the rest of the students. The finding of this study was yielded by a statistical examination of educational characteristics, family background, and personal and social resources. This distinction is valid for native-born Ethiopians as well as for Ethiopians who were born in Israel to parents who migrated from Ethiopia.

Initial Data for Higher Education: After conducting a Crosstabs analysis, we found the variables of students' education and origin to be interdependent.

Eligibility for matriculation is divided as follows: $79.7 \%$ of the Ethiopian students and $100 \%$ of the members of the control group hold matriculation certificates.

As stated previously, only some of the Ethiopian students $(\mathrm{N}=44)$ were accepted on the basis of their grades on the PET as one of the conditions for acceptance to an academic institution. We found a clear statistical difference between the Ethiopians' psychometric grades $(\dot{\mathrm{X}}=415.18 \pm 31.553)$ and those of the control group, in favor of the latter $(\dot{\mathrm{X}}=496.86 \pm 51.295), \quad\left(\mathrm{t}_{(62)}=9.380\right.$, $\mathrm{p}<0.01)$. Because of the small number of subjects, it was not possible to draw unequivocal conclusions regarding the differences in PET grades between the two groups. However, they are presented here since the results indicate a direction that is supported by previous studies (Almagor- Lotan \& Koch Davidovitz, 2011).

Although the range variations between the grades are smaller than the disparity identified in a previous study, namely, 108 points (ibid., 2011), the 
control group's average grade was still higher than the research group's average grade by approximately 80 points. Thus, the initial data of the Ethiopian subjects as measured by the PET were lower than those of the general subjects.

In conclusion, the findings demonstrate that Ethiopian students come to the colleges with initial academic data that are poor in relation to the rest of the students from the point of view of entrance and higher education data, namely; PET grade and eligibility for a matriculation certificate. These differences are reflected in the standard tools for acceptance to studies.

\section{Family Background Characteristics}

Parents' Education: A Crosstabs analysis reveals mother's and father's education were interdependent with student's origin. As regards mother's education, in the Ethiopian group, the mothers were the ones with a low level of education: $62.5 \%$ lacked any kind of education and $29.2 \%$ had elementary education. In contrast to the mothers of the students in the control group, $0 \%$ lacked any kind of education and 79.5\% had elementary education. Moreover, among the father's education for Ethiopians, $58.8 \%$ of the fathers lacked any kind of education and $9.4 \%$ had elementary education. Conversely, in the control group, $78.9 \%$ of the fathers had elementary education and only $2.6 \%$ lacked any kind of education.

In other words, the Ethiopian students' parents were either completely lacking in education or had a higher rate of elementary education as compared to the control group's parents.

Parents' Occupations: Mother's work and student's origin were interdependent. Of the Ethiopian student's mothers, $58.2 \%$ worked for a living as compared with $89.5 \%$ of the control group's mothers. Furthermore, there is interdependency between father's work and student's origin. In the control group, $89.7 \%$ of the fathers worked for a living; while in the research group, only $66.0 \%$ did so.

The Ethiopian students' mothers and fathers participated less in the work market than the parents of the rest of the students. Overall, the demographic characteristics of both students and parents presented here indicate the Ethiopian population to be weak as concerns the components of their status, education, and work.

\section{Personal Resources}

Goals: Four types of goals were identified among the students who were examined: (1) goals linked to studies/self-realization, (2) goals linked to free time, (3) goals linked to health and social resources, and (4) goals linked to everyday tasks.

Also, we found the group to which the subject belonged and the first goal to be interdependent. According to the cross-section table, a clear statistical difference between the distribution of the control group and the distribution of the research group was found. Therefore, the first goal chosen by the Ethiopian group was the studies/self-realization goal in $90.6 \%$ of cases. Furthermore, $65.9 \%$ of the control group opted for the studies/self-realization goal as their first goal, while $22 \%$ chose goals which were linked to social resources.

Thus, the Ethiopian youngsters as a group have elevated academic studies to a central goal at this stage in their lives as opposed to the other students who, in 
addition to studies, are related to other goals such as social goals. This is similar to current findings regarding minorities in colleges of education (Author et al., 2015).

Self-criticism, Criticism of Others, Self-efficacy, and Success: In a t-test for comparing averages in two independent samples, we found a clear statistical difference between self-criticism in the Ethiopian group and in the control group. The average self-criticism was higher in the control group $\left(\mathrm{t}_{(109)}=2.734, \mathrm{p}<0.05\right)$. Thus, a lower degree of self-criticism may facilitate Ethiopian students' advancement and adaptation. In the literature, the characteristic of a high level of self-criticism is perceived as limiting personal advancement (Author, 2007).

While no clear statistical difference concerning self-efficacy was found between the students in the two groups $\left(\mathrm{t}_{(109)}=0.699, \mathrm{p}>0.05\right)$, this variable was found to be a predictor of success in studies for the Ethiopians, as will be described in the next section.

As concerns the perception of success in studies, we did not find a clear statistical difference between the individual's success as compared with that of the others on the both groups.

Among the personal resources, it was self-criticism that differentiated between the two groups. In contrast, the measures of self-efficacy and the perception of success as compared with the others are general measures that are required of all the students and not just the students from particular groups.

Coping Resources - Coherence: According to a t-test, out of the three coherence measures, a clear statistical difference in coherence-manageability between the research group and the control group was found. Coherencemanageability was higher in the research group $\left(\mathrm{t}_{(109)}=2.28, \mathrm{p}<0.05\right)$. Ethiopian students reported on self-coping resources when dealing with assignments and also identified the coping tools at their disposal more than the students in the control group.

Thus, the sense of coherence-manageability, in addition to a low level of criticism, was perceived as a personal resource characterizing Ethiopians.

Motivation: A t-test failed to reveal clear differences between the research group and the control group in three of the motivation variables. However, Pearson's correlations within the groups reveal some statistical correlations that indicate the existence of a different pattern of ties between the type of motivation and other variables in each of the groups.

Among the Ethiopians, inner motivation was associated with a sense of selfefficacy; while in the control group, it was associated with success in the present and future and coherence-meaningfulness. External motivation for the Ethiopians was linked to grades and a sense of success in the present. However, for the control group, it was linked to pedagogy grades, coherence (comprehensibility and manageability), and criticism and self-efficacy.

To sum up, the research shows that it is important to relate to motivation according to its components and links to other variables rather than as a single measure. When splitting its components, the existence of differences between the groups can be understood.

\section{Social Resources}

A clear statistical difference was found between the human resource of the father, a partner/ friend and a spouse as social resources in the Ethiopian group 
and the same resource in the control group. The average of the human resource of the father was higher in the control group $\left(\mathrm{t}_{(92)}=2.75, \mathrm{p}<0.01\right)$.

The average of the human resource of a partner was higher in the control group $\left(\mathrm{t}_{(109)}=2.24, \mathrm{p}<0.05\right)$.

The average of the human resource of a spouse was higher in the control group $\left(\mathrm{t}_{(98)}=4.02, \mathrm{p}<0.01\right)$.

In other words, the students in the control group had additional resources that the Ethiopians lacked: the support of the father and the support of friends or a spouse. While these constitute a different type of resource, they contribute to the areas of achievements and quality of life.

Grades at the End of the First Semester: An examination of the differences between the groups by means of a t-test revealed a clear statistical difference between the overall grade average of the research group and the overall average of the control group in the latter's favor $\left(\mathrm{t}_{(109)}=3.26, \mathrm{p}<0.01\right)$.

The semestrial average in all of the control group's courses was $88.64 \pm 5.004$ as opposed to the Ethiopians' grade average, which was $85.36 \pm 5.28$.

In an examination of the differences in the pedagogy grades-pedagogy studies being central to the teaching profession-no clear difference was found between the control group and the research group $\left(\mathrm{t}_{(109)}=1.112, \mathrm{p}>0.05\right)$. In addition, the Ethiopians' grades $(\dot{\mathrm{X}}=90.37, \pm 4.876, \mathrm{~N}=68)$, as opposed to the grades of the students in the control group $(\dot{\mathrm{X}}=91.37, \pm 4.089, \mathrm{~N}=43)$, were very close.

It is especially interesting that despite the differences mentioned in the initial data for higher education, there were no significant differences at the end of the first semester of academic studies.

\section{Predicting Academic Achievements}

Achievements in General Studies: Regression was carried out by means of a linear prediction model. The general model provided the size of prediction of explained difference of the factors associated with the predicted variable. The prediction was tested using two tools: the existing tool-the PET, and the new tool that was proposed in this research:

The PET: The test predicted - at a very low level $\left(\mathrm{r}^{2}=0.108\right)$ - the firstsemester grade average of all the students in the sample, but it did not predict the grade average of each group separately, neither in the control group $\left(\mathrm{r}^{2}=0.03\right)$ nor in the research group $\left(\mathrm{r}^{2}=0.05\right)$. A generalizing view of the research yielded the following findings:

Pedagogy Grades: As opposed to the PET grades, the course grades (general grade average), as examined at the end of the first semester, were predicted by means of the pedagogy grades and the teaching practice grades $\left(\mathrm{r}^{2}=0.49\right)$ in the entire sample. In the control group, the pedagogy grade predicted the general average at a lower level $\left(\mathrm{r}^{2}=0.22\right)$. In the research group, the strong predictors were the pedagogy grade as well as the teaching practice grade (with a negative correlation) $\left(\mathrm{r}^{2}=-0.63\right)$.

In other words, the Ethiopian students whose achievements in pedagogy were good also received good grades in the rest of the first-semester courses of the first year-to a greater extent than the rest of the students.

In contrast, the Ethiopian students who succeeded in most of the courses did not necessarily succeed in the teaching practice1. 
Grade Average: Among the resources that were examined, it was found that the grade average in the general sample was predicted $\left(\mathrm{r}^{2}=0.651\right)$ by social resources (the support of the father, a close friend, or another adult), and by the personal resources (coherence-comprehensibility, present perception of success, success in relation to others, and criticism of others (in an inverse correlation)). Motivation did not predict the grade average of all first-semester courses.

In both groups, personal and social resources were accepted as predictors of semestrial achievements. In the control group $\left(\mathrm{r}^{2}=0.68\right)$, the personal resource predictors were: the perception of success in relation to others-positive correlation, coherence-comprehensibility-negative correlation, and criticism of others-negative correlation. Also, the interpersonal resource predictors were father's support-negative correlation, and a friend's support-negative correlation.

In contrast to the control group, the research group's prediction of the grades by the same personal resources was stronger $(r=0.811)$. As opposed to the control group, the Ethiopians displayed self-efficacy - in a weak but clear positive correlation, and relationship with a spouse - in a positive correlation - as social resources (while the control group predicted another adult as a source of support-in a positive correlation).

As opposed to the coherence-comprehensibility that predicted success in inverse correlation in the control group, among the Ethiopians, the negative correlation was stronger. In other words, in both groups - especially the Ethiopians - whoever perceived his/her world as consistent and rational did not have a high grade average.

Table 1. Maximum Regression Analysis of the Questionnaire Factors Predicting the Score Average Among the Group of Ethiopian Students and the Control Group

\begin{tabular}{|c|c|c|c|c|c|c|}
\hline \multirow[b]{2}{*}{ Factor } & \multicolumn{3}{|c|}{$\begin{array}{c}\text { Ethiopian Students } \\
\qquad \mathrm{N}=68\end{array}$} & \multicolumn{3}{|c|}{$\begin{array}{l}\text { Control Group } \\
\qquad \mathrm{N}=43\end{array}$} \\
\hline & $\beta$ & SE B & $\mathrm{B}$ & $\beta$ & SE B & $\mathrm{B}$ \\
\hline Success in the present & .044 & .274 & .119 & -.010 & .465 & -.034 \\
\hline Success in the future & .083 & .595 & .616 & -.204 & 1.419 & -1.485 \\
\hline Success in relation to the others & $.394 * *$ & .333 & 1.193 & $.578 *$ & .797 & 2.194 \\
\hline Mother as social resource & -.039 & 1.018 & -.437 & -.007 & 3.176 & -.117 \\
\hline Father as social resource & $-.342 * *$ & .424 & -1.578 & $-.403^{*}$ & .836 & -1.838 \\
\hline Friend as social resource & $-.850 * *$ & .769 & -6.091 & $*_{-} .845$ & 2.429 & -8.671 \\
\hline Partner/Spouse as social resource & $.052 * *$ & .668 & .287 & .256 & 2.445 & 3.156 \\
\hline Another person as social resource & .885 & .897 & 4.287 & $* * 1.172$ & 1.478 & 6.043 \\
\hline Inner motivation & -.084 & .751 & -.788 & -.121 & 2.407 & -1.496 \\
\hline External motivation & -.146 & .559 & -.902 & .101 & 1.022 & .558 \\
\hline Indecision \& path-seeking motivation & .137 & .696 & .863 & .325 & 1.044 & 1.717 \\
\hline Coherence-comprehensibility & $-.370 * *$ & .582 & -2.420 & $*_{-} .483$ & 1.030 & -2.733 \\
\hline Coherence-manageability & .175 & .830 & 1.140 & .263 & 1.439 & 1.705 \\
\hline Coherence-meaningfulness & .110 & .778 & .742 & .191 & 1.867 & 1.147 \\
\hline Self-criticism & -.070 & .594 & -.443 & -.332 & .959 & -1.790 \\
\hline Criticism of others & $-.389 * *$ & .602 & -1.810 & $* *-.661$ & .969 & -2.794 \\
\hline Self-efficacy & $.176 *$ & .526 & -1.053 & .038 & 1.317 & .250 \\
\hline $\mathrm{R}^{2}$ & & 0.811 & & & 0.680 & \\
\hline $\mathrm{F}$ & & $k * 12.613$ & & & $* * 3.128$ & \\
\hline
\end{tabular}


Note. $\mathrm{B}=$ multiple regression; $\mathrm{SE} \mathrm{B}=$ standard error $\beta=$ standardized estimate of Beta; $\left({ }^{*} \mathrm{p}<0.05,{ }^{*} \mathrm{p}<0.01\right)$

\section{Achievements in the Pedagogy Course}

It should be mentioned that even prior to the calculated linear regression, the pedagogy grades were not predicted by the PET grade, by the general sample $\left(\mathrm{r}^{2}=0.034\right)$, by the control group $\left(\mathrm{r}^{2}=0.005\right)$, or by the research group $\left(\mathrm{r}^{2}=0.06\right)$.

Personal Skills: In the research group $\left(r^{2}=0.909\right)$, the pedagogy grade was predicted in a positive correlation by the following personal skills: the perception of success in relation to the others and coherence-meaningfulness, and in a negative correlation with the following variables: inner motivation, external motivation, the four human support resources (with the exception of another adult, which is in a very high positive correlation), coherence-comprehensibility, and criticism of others.

The prediction of the pedagogy grades by means of personal and social skills was very high in both groups and did not particularly characterize the Ethiopian group, except for the support of another adult and inner motivation in a negative correlation.

To sum up, from an examination of the correlations between the variables that characterize the prediction of the Ethiopian group's grades, the following picture emerges:

We found a clear statistical correlation with a high correlation coefficient $\left(r_{p}=0.772, p(0.01>\right.$ between pedagogy and the semestrial average; in other words, the Ethiopian group's achievements were at a relatively uniform level in all the courses, including pedagogy.

We also found good achievements in pedagogy to be linked to a sense of success in relation to the others with a medium correlation coefficient $\left(r_{p}=0.377\right.$, $\mathrm{p}>0.01)$ and to a subjective sense of success in the future in relation to the others $\left(\mathrm{r}_{\mathrm{p}}=0.455, \mathrm{p}>0.01\right)$.

Furthermore, we found that among the Ethiopians, a link existed between the sense of self-efficacy and self-criticism, with a medium negative correlation $(\mathrm{r} p=-0.372, \mathrm{p}>0.05)$. Here, the sense of efficacy related to another person or to the self' is a logical assumption that self-efficacy is only an inner sense and is not connected in comparison with the others.

Table 2. Maximum Regression Analysis of the Questionnaire Factors Predicting the Pedagogy Variable Among the Group of Ethiopian Students and the Control Group

\begin{tabular}{|c|c|c|c|c|c|c|}
\hline \multirow[b]{2}{*}{ Factor } & \multicolumn{3}{|c|}{$\begin{array}{l}\text { Ethiopian students } \\
\qquad \mathrm{N}=68\end{array}$} & \multicolumn{3}{|c|}{$\begin{array}{c}\text { Control group } \\
\mathrm{N}=43\end{array}$} \\
\hline & $\mathrm{B}$ & SE B & $\mathrm{B}$ & $\beta$ & SE B & $\mathrm{B}$ \\
\hline Success in the present & .024 & .176 & .061 & -.101 & .164 & -.273 \\
\hline Success in the future & .105 & .382 & .718 & .123 & .499 & .733 \\
\hline Success vis-e-vis the others & $.459 * *$ & .214 & 1.282 & $.532 * *$ & .280 & 1.647 \\
\hline Mother as social resource & $-.260 * *$ & .654 & -2.719 & $-.208^{*}$ & 1.117 & -2.864 \\
\hline Father as social resource & $-.317 * *$ & .273 & -1.354 & $-.298 * *$ & .294 & -1.110 \\
\hline Friend as social resource & $-.475 * *$ & .494 & -3.145 & $-.366 * *$ & .854 & -3.069 \\
\hline Partner, spouse as social resource & $-.401 * *$ & .430 & -2.029 & $-.269 * *$ & .860 & -2.709 \\
\hline Another person as social resource & $.825 * *$ & .577 & 3.693 & $.926 * *$ & .520 & 3.903 \\
\hline Inner motivation & $-.154 * *$ & .483 & -1.344 & -.084 & .847 & -.852 \\
\hline
\end{tabular}


Research Article

\begin{tabular}{c|ccc|ccc} 
External motivation & $-.257^{* *}$ & .359 & -1.461 & $-.311 * *$ & .360 & -1.406 \\
Indecision \& path-seeking motivation & .104 & .447 & .604 & $* .196$ & .367 & .845 \\
Coherence-comprehensibility & $-.594^{* *}$ & .374 & -3.585 & $* *-.748$ & .362 & -3.462 \\
Coherence-manageability & .041 & .533 & .244 & .032 & .506 & .171 \\
Coherence-meaningfulness & $.495 * *$ & .500 & 3.074 & $* * .526$ & .657 & 2.579 \\
Self-criticism & -.087 & .382 & -.512 & $*-.162$ & .337 & -.713 \\
Criticism of others & $-.305 * *$ & .387 & -1.312 & $* *-.410$ & .341 & -1.415 \\
Self-efficacy & .051 & .338 & .284 & .067 & .463 & .361 \\
$\mathrm{R}^{2}$ & & 0.909 & & & & \\
$\mathrm{~F}$ & & $* * 941$ & & \\
\hline
\end{tabular}

Note. $\mathrm{B}=$ multiple regression; $\mathrm{SE} \mathrm{B}=$ standard error $\beta=$ standardized estimate of Beta; $\left({ }^{*} \mathrm{p}<0.05,{ }^{* *} \mathrm{p}<0.01\right)$

\section{Conclusions and Discussion}

This present research presents two types of findings. The first type relates to significant differences in background data, in first-semester grades, and in personal and social resources between the group of Ethiopian students and the general group of students. The second type of information relates more specifically to the prediction of academic achievements on the basis of personal and social variables as opposed to the usual prediction on the basis of the PET.

\section{Differences in Background Data, First-Semester Grades, and Personal and Social Resources}

Second and first-and-a-half-generation Ethiopian immigrants to Israel approached academic studies with poorer personal potential for studying. Their background data were basic or even less as compared with most of the students, whose parents had received elementary education and more, and whose percentage of maternal and paternal employment was higher than that of the Ethiopian parents. The Ethiopian students attained grades that were some 80 points lower on the PET than the other students, and some of them held certificates from preparatory courses rather than matriculation certificates.

The background data affected the manner in which the encounter between the two groups of students occurred. In this encounter, the Ethiopians sought a place for themselves in academia despite their poor skills and their parents' education and low employment percentage, all of which posed considerable personal, social, and academic challenges for their integration into academia. Due to their background data, the road to academia was longer and more complex for them than it was for their counterparts.

The research also revealed a discrepancy in the PET grades between the two groups, to the detriment of the Ethiopians. This supports the prior claims stating that the PET is liable to be culturally biased, and that the conditions of acceptance to institutions of higher education are the result of supply and demand rather than that of the level of difficulty of the actual studies (GuriRosenblit, 2000; Turvall, Bronner, Kennet-Cohen, \& Oren, 2008).

Similar to other minority groups, among the personal resources at the disposal of the Ethiopians, was first and foremost the choice of studying as a primary goal at this stage of their lives (Author et al., 2015). Therefore, this is in 
contrast to the students from the majority group who opted for studying as a primary goal in life at a lower rate and in parallel also to the selected social goals.

The combination of the background data and the PET grade placed the Ethiopian students in a doubly inferior situation since they had to rally many powerful personal resources. This combination may explain the fact that they positioned academic studies at the head of their hierarchy of goals. Hence, these students may have considered their entry into academia to be an opportunity to improve the reality of their lives. The fact that they placed their studies ahead of all the other personal goals is a declaration of intent emanating from the following realization: this was a critical point in time for their future integration into the employment market and for the creation of better possibilities of social mobility as well as of a higher socioeconomic status than that of their parents. Furthermore, entry into academia occasionally entails a "pioneering" feat. Many students reported being the first in their families to seek higher education (ibid), thereby serving as an example for their younger siblings and undergoing an empowering experience.

Similar to the present finding regarding Ethiopians, previous studies (Author, 2007) revealed that successful preparatory-course pupils displayed a low rate of self-criticism. This afforded them the requisite flexibility for adapting to changing circumstances and rising to the challenge of finding alternative solutions to situations of crises.

Another resource that the Ethiopians were found to possess was the perception of coherence-manageability. It appears that this perception was developed as a result of the need to cope with the reality of their lives. In immigrant families, the sons sometimes assume additional roles that are usually adult roles (such as taking care of siblings, assisting their parents financially). It is possible that these exigencies bestow upon them the perception that they possess the resources and the ability to cope with various situations, including entry into academia.

In contrast to the resources that differentiated between the groups, there were also common resources: self-efficacy, the perception of success, and motivation. Evidently, these resources are essential for all students in order to handle their studies. It is also possible that the reason for the absence of differentiation in these resources resides in the measuring tool itself. This approach stems from the fact that when a coherence-manageability check was used (this also attests to a sense of efficacy), it was in fact the Ethiopians who had a considerable advantage over the rest of the students.

It is particularly interesting that the motivation variable, which the research (Assor, 2012; Shahar et al., 2006) has shown to be effective for predicting academic achievements, failed to differentiate between the two groups in the present study. Conversely, correlations were found between the different motivation patterns and other personal resources. These may attest to a different pattern in each of the two groups' perception of motivation.

It appears that the Ethiopians perceived inner motivation as a generalized sense that motivated them along their life paths as opposed to the other students for whom inner motivation was associated with recruiting practical skills that would help them attain genuine achievements. Among the students from the control group, external motivation was found to be linked in the opposite manner 
to inner perceptions (such as efficacy, criticism, coherence-comprehensibility), thus exhibiting a type of negative image of inner motivation.

From the point of view of the social resources, the students in the control group were found to possess additional resources that the Ethiopians did not: paternal support and the support of friends and spouse. These are resources whose contribution has been proven in the domains of achievements and quality of life (Bridges et al., 2006; Shulman \& Connolly, 2013). However, this lack can be explained by considering the disadvantages of migration from the viewpoint of familial and interpersonal support. Some of the migrants leave behind family members, friends, and others who are close to them in their countries of origin. Young migrants who arrive in Israel with their families are sometimes compelled to assume the role of their parents since the latter are not available to serve as an effective safety net while they are involved with their own absorption into the new country. Moreover, the lack of familial resources perceptions may explain the cultural disparity experienced by the students. It is possible that in the process of adaptation, they experienced a need for mingling socially with their contemporaries and with the "Israeli culture", thereby transforming their parents into the representatives of their former culture, which is perceived by many youngsters as obsolete.

Furthermore, based on the students' background data, family, and some of the friends were ignorant of the academic system, they were therefore unable to serve in an advisory capacity. In contrast, it should be mentioned that in other parts of the acceptance process (personal interview), they mentioned their profound emotional link with their parents.

\section{Prediction of Academic Achievements Based on Personal and Social Variables as Opposed to the Regular Prediction of the PET}

As regards the prediction of academic achievements, the PET was found to predict the general grade average of both groups together at a very low level. On the other hand, it totally failed to predict the achievements of each group separately. In addition, the PET grade was not found to predict the students' achievements in pedagogy. It could be stated that with regard to the students in this study, the PET was not proven to be a satisfactory means of predicting achievements in the first-year courses as they had been measured at an earlier stage, namely, at the end of the first semester. Pedagogical studies combine cognitive, social, and emotional aspects, and therefore the prediction of a test based solely on a cognitive component is inappropriate for predicting success in the performance required from a student teacher.

As opposed to the absence of prediction in the PET, the good achievements in pedagogy predicted the Ethiopian students' (more than the other students') good grade average in all the other courses. One can understand from this that when there are personal resources, they come to the fore in the general level of performance in most areas of the study and during the actual study period. Thus, there is no advantage to the PET's preliminary prediction. The opposite may even be true on the personal level. Also, the PET may pose an obstacle that is liable to diminish the student's motivation; and its use may increase the risk of losing good students precisely as a result of the use of a tool that is unsuitable for a unique population. On the social level, there is a type of social exclusion of 
certain groups that are not afforded an equal opportunity that is tailored to their characteristics in order to be accepted to academia.

As opposed to the pedagogy grade, the grade in teaching practice did not predict general achievements among the Ethiopians; it did, however, predict them in the control group. The reason for this may be that teaching practice requires additional applied skills that differ from the personal skills needed in the general courses and in pedagogy. These include verbal, representative, and communicative abilities that the Ethiopians as a group did not possess beforehand. It is highly likely that this exerts a negative influence on their performance in the practicum setting (Brenner, 2015).

Some, but not all, personal and social skills predicted academic achievements in both groups: the perception of the ability to succeed in relation to the others, the perception of the inner and external world as predictable and rational (coherence-comprehensibility) in a negative correlation, and the criticism of others in a negative correlation characterized the two groups. In other words, whoever believes that he/she can succeed in relation to others does in fact succeed. However, whoever perceives the world as predictable and rational and is also critical of others is not among those with a high grade average. It seems that these variables possess a component of the individual's perception of society and not only self-perception. Among Ethiopians, this perception may be an expression of disappointment or a pessimistic view of the surrounding society on the one hand, and of the belief in their ability to overcome on the other hand. This notion is reinforced by the high-level coping powers that have been identified, namely, coherence-manageability and the sense of self-efficacy, which are resources that characterize only Ethiopians.

As concerns the pedagogy grades, no difference was found between the two groups. This datum in particular permits conclusions to be drawn concerning Ethiopian students. Despite the initial disparities in the initial academic data of the groups in the measures mentioned previously, the pedagogy grade at the end of the first semester, which did not favor the group that commenced with better initial data, was high in both groups.

The study proves that the pedagogy grade was predicted by the personal and social resources in the two groups. Also, it did not characterize the research group in particular. Accordingly, it can be suggested that some of the tools used in the research can be employed during the acceptance process of all populations studying education.

In conclusion, significant differences were found in the resources characterizing each of the two groups. In addition, a response to the question of predicting general academic achievements by means of personal skills was found. Among Ethiopians, the perception of coherence-manageability and the perception of selfefficacy are the unique predictors.

\section{Recommendations}

Among the suggestions that can be derived from this research, it is desirable that beyond the cognitive skills of the Ethiopians who seek acceptance to higher education, their coping powers can also be examined. This is because these may well offer a foretaste of their true academic performance. Moreover, it is 
recommended that those involved in teacher education as well as the decision makers in the education system should increase their acquaintance with Ethiopians as a distinct group with unique characteristics that may well contribute to the education system.

Therefore, such an approach may somewhat ease the sense of generalized disillusionment experienced by the members of the Ethiopian community. The veteran immigrants arrived in Israel out of ideological motives; however, their encounter with Israeli society was disappointing and failed to result in their egalitarian integration, as they had hoped, when they left Ethiopia (Ben Ezer, 2007; Malko, 2005). Furthermore, among the second and first-and-a-half generations, the disparity is still evident.

Consequently, the appropriate classification of Ethiopian candidates for the acceptance to institutions of higher education conforms to the perception that upholds a differential mode of relating to differences on the one hand and a view of the goals of equal opportunities and accessibility to higher education on the other hand.

\section{References}

Al-Krenawi, A., \& Slonim Nevo, V. (2009). The perception of mentally disabled children in the Bedouin Arab family and its effect on the family's function and self-image. Final scientific report, submitted to the Shalem Fund for Development of Services for People with mental Retardation in the Local Councils. Ben Gurion University, Beer Sheva, Israel. [in Hebrew]. Retrieved from

http://www.kshalem.org.il/uploads/pdf/article_4158_1375388918.pdf

Almagor-Lotan, O., \& Koch Davidovich, F. (2011). The Integration of Persons of Ethiopian Origin into the Higher Education System. Jerusalem, Israel: The Knesset, Center for Research and Information. Retrieved from

https://knesset.gov.il/mmm/data/pdf/me02892.pdf

Antonovsky, A. (1993). The structure and properties of the sense of coherence scale. Social Science \& Medicine, 36(6), 725-733. doi:10.1016/0277-9536(93)90033-Z

Antonovsky, A., \& Sagy, S. (1986). The development of a sense of coherence and its impact on responses to stress situation. Journal of Social Psychology, 126 (2), 213-225.

Assor, A. (2012). Autonomous moral motivation: Consequences, socializing antecedents and the unique role of integrated moral principles. In M. Mikulincer, \& P. R. Shaver (Eds.), The social psychology of morality: Exploring the causes of good and evil (pp. 239-255). Washington, D.C.: American Psychological Association.

Ben-Ezer, G. (2007). The journey: Stories of the journey of Ethiopian Jewry to Israel, 1977-1985. Ben Shemen, Israel: Modan. [in Hebrew]

Blatt, S. J., \& Blass, R. B. (1996). Relatedness and self definition: A dialectic model of personality development. In G. G. Noam, \& K. W. Fisher (Eds.), Development and vulnerabilities in close relationships (pp. 309-338). Hillsdale, NJ: Lawrence Erlbaum Associates.

Blatt, S. J., Shahar, G., \& Zuroff, D. C. (2001). Analytic (sociotropic) and introjective (autonomous) dimensions. Psychotherapy, 38, 449-454.

Brenner, R. (2015). Ethiopian kindergarten teachers in the education system: A change in attitude will lead to success. Hed Hagan, Quarterly for Early Childhood Education, B, 38-43. [in Hebrew]

Bridges, M., Flores, E., Tschann, J., \& Operario, D. (2006). Brief report: Associations of parental warmth, peer support, and gender with adolescent emotional distress. Journal of Adolescence, 29(2), 299-305. doi:10.1016/j.adolescence.2005.07.001

Cahan-Stravachinsky, P. F., Levy, D. \& Constantinov, V. (2012). Immigrant youngsters from Ethiopia and immigrant youngsters from the FSU: Immigrants and children of immigrants similarity and difference. Jerusalem, Israel: Myers-JDC-Brookdale Institute. [in Hebrew] 
Central Bureau of Statistics. (2013). Announcement to the press: The Ethiopian population in Israel, selected data on the occasion of the Sigd Holiday. Retrieved from

http://cbs.gov.il/www/hodaot2013n/11_13_300e.pdf

Cohen, Y., \& Haberfeld, Y. (2003). Economic integration among children of Israeli immigrants in the United States. International Migration, 41(4), 141-159. doi: 10.1111/1468-2435.00255

Cook Golan, P. F. (2008). Language acquisition in a multicultural and multilingual context: Bilingual identity and orientation: Inclinations and behavior patterns among immigrant students from the FSU in Israel. Hed Ha'Ulpan Hehadash, 94. (Autumn) [in Hebrew]

Dietrich, J., Shulman, S., \& Nurmi, J. E. (2013). Goal pursuit in young adulthood: The role of personality and motivation in goal appraisal trajectories across six years. Journal of Research in Personality, 47(6), 728-737. doi:10.1016/j.jrp.2013.06.004

Edelstein, A. (2002). Patterns of misdemeanors and delinquency among Ethiopian youngsters in Israel. Police \& Society, 6 (August), 5-32. [in Hebrew]

Feivish, R., \& Goldschmidt, R. (2006). Methods of acceptance to institutions of higher education: Comparative survey. Jerusalem: The Knesset, Center for Research and Information. [in Hebrew]. Retrieved from

https://www.knesset.gov.il/mmm/data/pdf/m01518.pdf

Furman, W., \& Buhrmester, D. (1985). Children's perceptions of the personal relationships in their social networks. Developmental Psychology, 21(6), 1016-1024. http://dx.doi.org/10.1037/00121649.21.6.1016

Furman, W., \& Buhrmester, D. (1992). Age and sex differences in perceptions of networks of personal relationships. Child Development, 63(1), 103-115. doi: 10.1111/j.1467-8624.1992.tb03599.x

Galambos, N., Barker, E., \& Krahn, H. (2006). Depression, self-esteem, and anger in emerging adulthood: Seven-year trajectories. Developmental Psychology, 42(2) 350-365. http://dx.doi.org/10.1037/0012-1649.42.2.350

Guri-Rosenblit, S. (2000). Access to higher education: An international perspective. in S., GuriRosenblit (Ed.), Access to Higher Education: Social Perspectives and Selection Mechanisms (pp. 11-25). Jerusalem: Van Leer Institute [in Hebrew]

Author, E. (2007). The role of personal and social resources in coping with disruptions during the transition to adulthood. Doctoral dissertation, Bar-Ilan University, Ramat Gan, Israel [in Hebrew]

Author, E. (2013). Increasing access to higher education and employment: Ethiopian immigrants in Israel. Intercultural Education, 24(5), 476-488. doi: 10.1080/14675986.2013.844580

Author, E., et al. (2015). Islands of hope in a stormy sea: Perceptions of students from minority groups in colleges of education. Tel Aviv, Israel: The MOFET Institute. [in Hebrew]

Karlitz, T., Ben-Simon, A., Ibrahim, R., \& Eviatar, Z. (2014). Differences between Hebrew-speakers and Arabic-speakers in efficiency of reading texts in the mother-tongue. Jerusalem: National Center for Examinations and Evaluation. [in Hebrew]

King, I., \& Valda Tzadik, A. (2006). Patterns of Integration into employment

of immigrants aged 22-64 (pp. 18-56). Jerusalem, Israel: Myers-JDC-Brookdale Institute. [in Hebrew]

Lev Ari, L. (2012). Second generation and 'first-and-a-half generation' of Israelis in North America: Identity and identification: Comparison among three groups (members of the "Tzabar" groups and others). Ramat Gan, Israel: Rappaport Center for Assimilation, Research, and the Strengthening of Jewish Vitality, Bar-Ilan University. [in Hebrew]

Little, B. R. (1983). Personal projects: A rationale and method for investigation. Environment and Behavior, 15(3), 273-309. doi: 10.1177/0013916583153002

Little, T. D., Cunningham, W. A., Shahar, G., \& Widaman, K. F. (2002). To parcel or not to parcel: Exploring the question, weighing the merits. Structural Equation Modeling, 9,(2) 151-173. doi:10.1207/S15328007SEM0902_1

Malko, G. (2005). We have nothing to offer you. In Zion that failed: The Jews of Ethiopia in Israel. Eretz Aheret 30 (November), 76-80. [in Hebrew]. Retrieved from

http://eretzacheret.org.il/\%D7\%90\%D7\%99\%D7\%9F-\%D7\%9C\%D7\%A0\%D7\%95-\%D7\%9E\%D7\%94\%D7\%9C\%D7\%94\%D7\%A6\%D7\%99\%D7\%A2-\%D7\%9C\%D7\%9B\%D7\%9D/

Mana, A., Or, A., \& Mana, Y. (2004). The identity of adolescents from Ethiopia and the FSU: Organizational principles of a unique cultural representation of absorption and immigration. Megamot, 43, 491-519. [in Hebrew]

Romano, J. L. (2015). Prevention psychology: Enhancing personal and social well-being. Washington, D.C.: American Psychological Association.

Ryan, R. M., \& Connell, J. P. (1989). Perceived locus of causality and internalization: Examining reasons for acting in two domains. Journal of Personality and Social Psychology, 57(5), 749-761. http://dx.doi.org/10.1037/0022-3514.57.5.749 
Ryan R. M., \& Deci, E. L. (2000). Intrinsic and extrinsic motivations: Classic definitions and new directions. Contemporary Educational Psychology, 25(1), 54-67. doi:10.1006/ceps.1999.1020

Tartas, M., Walkiewicz, M., Budzinski, W., Majkowicz, M., \& Wojcikiewicz, K. (2014). The sense of coherence and styles of success in the medical career: A longitudinal study. BMC Medical Education, 14, 254. http://doi.org/10.1186/s12909-014-0254-5

Sanders, M., \& Ralph, A. (2005). Family intervention and prevention of behavioral and emotional disorders in childhood and adolescence. In J. L. Hudson, \& R. M. Rapee (Eds.), Psychopathology and the family (pp. 323-350). New York, NY, US: Elsevier Science.

Schleifer, M. (2007). Development of the capacity to produce written discourse in children and immigrant children from Ethiopia to Israel: Linguistic, social, cultural and cognitive aspects. Hed Ha'ulpan Hehadash, 91. [in Hebrew]

Shabtai, M. (2001). Living with a threatening identity: Life experiences with a difference in skin color among Ethiopian youngsters and adolescents in Israel. Megamot, 41(1-2), 97-112. [in Hebrew]

Shabtai, M., \& Kasan, L. (2005). (Eds.). 'Mulualam': Ethiopian women and girls in spaces, worlds and journeys between cultures. Tel Aviv, Israel: Lashon Tzeha. [in Hebrew]

Shahar, G., Henrich, C., Blatt, S. J., Ryan, R., \& Little, T. (2003). Interpersonal relatedness, selfdefinition, and their motivational orientation during adolescence: A theoretical and empirical integration. Developmental Psychology, 39(3), 470-483. doi: 10.1037/0012-1649.39.3.470

Shahar, G., Author, E., Shulman, S., \& Blatt, S. J. (2006). Personality, motivation, and the construction of goals during the transition to adulthood. Personality and Individual Differences, 40(1), 53-63. doi:10.1016/j.paid.2005.06.016

Shulman, S., \& Connolly, J. (2013). The challenge of romantic relationships in emerging adulthood: Reconceptualization of the field. Emerging Adulthood, 1(1), 26-39. http://eax.sagepub.com/content/1/1/27.full

Shulman, S., Author, E., \& Shahar, G. (2009). Meeting developmental challenges during emerging adulthood: The role of personality and social resources. Journal of Adolescent Research, 24(2), 242-267. doi: $10.1177 / 0743558408329303$

Shulman, S., \& Nurmi, J. E. (2010). Dynamics of goal pursuit and personality make-up among emerging adults: Typology, change over time, and adaptation. New Directions for Child and Adolescent Development ,2010(130), 57-70. doi: 10.1002/cd.281

Turvall, E., Bronner, S., Kennet-Cohen, T., \& Oren, C. (2008 July). Fairness in the higher education admissions procedure: The Psychometric Entrance Test in Arabic. Jerusalem: National Institute for Testing and Evaluation.

Tzuriel, D., \& Kaufman, R. (1999). Mediated learning and cognitive modifiability: Dynamic assessment of young Ethiopian immigrants in Israel. Journal of Cross-Cultural Psychology, 30(3), 359-380. doi: 10.1177/0022022199030003005

Wilson, J., Ward, C., \& Fisher, R. (2013). Beyond culture learning theory: What can personality tell us about cultural competence?. Journal of Cross-Cultural Psychology, 44(6), 900-927. doi: 10.1177/0022022113492889 